\title{
Attachment and coparenting representations in men during the transition to parenthood
}

\author{
Tiago Miguel Pinto (iD) | Bárbara Figueiredo
}

University of Minho, Braga, Portugal

Correspondence

Tiago Miguel Pinto, School of Psychology,

University of Minho, Campus of Gualtar,

4710-057 Braga, Portugal

Email: tmpinto@psi.uminho.pt

Funding Information

Portuguese Foundation for Science and Technology Portuguese Ministry of Education and Science FEDER COMPETE2020 under the PT2020 Partnership Agreement Number: POCI-01-0145-FEDER-007653 Operacional Factores de Competitividade-COMPETE FCT-Fundação para a Ciência e a Tecnologia Grant SFRH/BD/115048/2016. This study was also supported by FCT under the project PTDC/SAU/SAP/116738/2010.

\begin{abstract}
Coparenting is based on parents' representations of themselves as coparents. Attachment theory can be a useful framework to understand the way that different coparenting representations are developed during the transition to parenthood. This study aimed to analyze the association between men's attachment and coparenting representations at the first trimester of pregnancy and from the first trimester of pregnancy to 6 months' postpartum. A sample of 86 men was recruited and completed self-report measures of attachment and coparenting representations at the first and third trimester of pregnancy and at 1 and 6 months' postpartum. At the first trimester of pregnancy, higher attachment avoidance was associated with higher lack of coparenting support. From the first trimester of pregnancy to 6 months' postpartum, higher attachment avoidance was associated with (a) a steeper increase on lack of coparenting support, (b) an increase on coparenting conflict (while low attachment avoidance was associated with a decrease), and (c) a lower decrease on coparenting disagreement. This study may contribute to coparenting research by showing new evidence on attachment theory as a useful framework to understand how different coparenting representations are developed in men during the transition to parenthood.
\end{abstract}

\section{K E Y W O R D S}

attachment tendencies, coparenting representations, men, transition to parenthood

\section{1 | INTRODUCTION}

According to the attachment theory, adults develop significant relationships based on their attachment tendencies. Attachment tendencies include a wide range of memories, beliefs, and expectations that shape how individuals think and feel about their relationships and how they behave in those relationships (Bowlby, 1969; Shaver \& Hazan, 1988). Attachment theory refers to these tendencies as internal working models of attachment that once developed are highly stable and are carried forward into adolescent and adult relationships (Bowlby, 1969; Shaver \& Hazan, 1988). Internal working models play an important role in guiding perception, emotion, and behavior in attachment-related situations (e.g., Ammaniti, van IJzendoorn, Speranza, \& Tambelli, 2000; Collins \& Allard, 2001; Fraley \& Roberts, 2005).
As previously observed in infants, adults look for the proximity of significant others, experience emotional distress if the other is not available, build up confidence and security from the relationship with the other, and look for the other in situations of distress and threat (Ainsworth, 1989; Collins \& Feeney, 2004; Shaver \& Mikulincer, 2007). Looking for support, for example, refers to a behavioral manifestation of the attachment system, and the availability of the attachment figure is associated with individual psychological adjustment, even in adulthood (Collins \& Feeney, 2000; Feeney \& Collins, 2004).

The attachment literature has explored individual differences in adult attachment tendencies (e.g., Bartholomew, 1990; Bartholomew \& Shaver, 1998). These tendencies are patterns of thinking, feeling, and behaving in significant relationships, and reflect individual differences in internal 
working models of the self and of the relationships with others (e.g., Collins, Ford, Guichard, \& Allard, 2006). Bartholomew and Shaver (1998) proposed a model of adult attachment that conceptualizes attachment in two dimensions: (a) avoidance, which corresponds to the discomfort with the closeness or dependency and the reluctance to be intimate with others; and (b) anxiety, which corresponds to the vigilance toward the rejection and abandonment. Attachment avoidance consists of a deactivation of the attachment system in situations of distress. Individuals suppress their attachment-related affects and deny their attachment needs (e.g., Bartholomew, 1990; Bartholomew \& Shaver, 1998). Avoidant attached individuals seek to maintain independence and self-reliance while denying needs or emotional states that could activate the attachment system (e.g., Mikulincer, Shaver, \& Pereg, 2003; Shaver \& Mikulincer, 2007). As such, highly avoidant individuals often do not allow themselves to become close to significant others or do not turn to others for support in situations of distress (e.g., Campbell, Simpson, Kashy \& Rholes, 2001; Simpson, Rholes, \& Nelligan, 1992). Conversely, attachment anxiety consists of a hyperactivation of the attachment system in situations of distress. Individuals worry and ruminate about being rejected or abandoned by significant others. Anxious attached individuals make strong attempts to maintain proximity to their attachment figures and closely monitor the others for signs of rejection or to achieve physical or emotional proximity (e.g., Simpson, Ickes, \& Grich, 1999).

Both men's attachment avoidance and anxiety were associated with lower marital relationship quality (e.g., Fraley \& Bonanno, 2004; Kafetsios \& Sideridis, 2006; Millings \& Walsh, 2009; Selcuk, Zayas, \& Hazan, 2010). Higher men's attachment avoidance was associated with lower levels of intimacy and commitment in their marital relationships whereas higher men's attachment anxiety was associated with higher jealousy, and higher perceived conflict in marital relationships (e.g., Fraley \& Bonanno, 2004; Selcuk et al., 2010).

The transition to parenthood is a major life event that leads both men and women to perform several developmental tasks to adapt to a wide range of biological, psychological, and sociocultural changes (e.g., Cowan \& Cowan, 2000; Figueiredo, 2014). According to attachment theory, the transition to parenthood can be a stressful event that activates the attachment system (Rholes, Simpson, Campbell, \& Gric, 2001). Constructing a coparenting relationship is an important developmental task within the transition to parenthood (e.g., Altenburger, Schoppe-Sullivan, Lang, Bower, \& Kamp Dush, 2014; Favez, Frascarolo, Scaiola, \& Corboz-Warnery, 2013; Figueiredo, 2014; Van Egeren, 2004). This relationship is progressively developed across the transition to parenthood and is already operative during pregnancy (e.g., Altenburger et al., 2014; Favez et al., 2013; Van Egeren \& Hawkins, 2004), when parents start to develop representations of themselves as coparents (e.g., Feinberg, 2003; Van Egeren, 2003).
From this perspective, when partners start to discuss issues related to coparenting (e.g., how they will manage caregiving together) they already have begun a coparenting relationship, long before childbirth (e.g., Altenburger et al., 2014; Favez et al., 2013; Van Egeren \& Hawkins, 2004). Coparenting is defined as the reciprocal involvement of both parents in education, responsibilities, and decisions about their children's lives, focusing interparental interactions associated to adults' functions and expectations about their parents' role. This dyadic relationship refers specifically to the coordination and support that each coparent provides to the other in childcare (quality and frequency) (Feinberg, 2002). Feinberg (2003) proposed an empirically based coparenting ecological model, conceptualizing coparenting in four interrelated dimensions: (a) the agreement or disagreement on childrearing issues, (b) the division of labor, (c) the support versus undermining for the coparental role, and (d) the joint management of family interactions.

The way that both parents adjust to their new roles as coparents is influenced by multiple factors. Feinberg's (2003) ecological model suggests that coparenting is shaped by four main factors: individual parental characteristics, child characteristics, interparental relationship, and stress and support contextual sources. According to the attachment theory, internal working models shape the way adults develop significant relationships (Ammaniti et al., 2000; Collins \& Allard, 2001; Fraley \& Roberts, 2005). A previous study found a negative association between men's secure attachment and coparenting conflict during the postpartum period (Talbot, Baker, \& McHale, 2009). Attachment theory can be a useful framework to understand the way that different coparenting representations are developed during the transition to parenthood. Addressing this hypothesis, the current study aimed to analyze the association between men's attachment and coparenting representations at the first trimester of pregnancy and from the first trimester of pregnancy to 6 months' postpartum.

\section{2 | METHOD}

\section{1 | Participants}

The sample was comprised of 86 primiparous men recruited at the first trimester of pregnancy in two obstetrics outpatients units in Portugal. Exclusion criteria were: not read or write in Portuguese, live in Portugal in time less than 10 years, single men or not living with the partner, multiparous men, multiple gestations, and pregnancies with gestational problems. From the 130 participants contacted, 121 (93.1\%) agreed to participate, and 91 (70.0\%) signed an online informed consent form. From the 86 participants who completed the first assessment, $51(59.3 \%)$ completed all assessment waves.

All participants were married or cohabiting. Nearly all participants were Portuguese (96.7\%), Caucasian $(87.9 \%)$, 
TA B L E 1 Men's sociodemographic characteristics at the first trimester of pregnancy (baseline)

\begin{tabular}{|c|c|c|}
\hline Characteristic & & $\begin{array}{l}\mathbf{N}=\mathbf{8 6} \\
\%\end{array}$ \\
\hline \multirow[t]{3}{*}{ Age (years) } & $20-29$ & 35.2 \\
\hline & $30-39$ & 62.6 \\
\hline & $40-45$ & 2.2 \\
\hline \multirow[t]{3}{*}{ Socioeconomic level } & High & 33.3 \\
\hline & Medium high & 59.0 \\
\hline & Low & 7.7 \\
\hline \multirow[t]{2}{*}{ Occupational status } & Employed & 89.0 \\
\hline & Unemployed & 11.0 \\
\hline \multirow[t]{3}{*}{ Schooling (in years) } & $<9$ & 9.9 \\
\hline & $9-12$ & 52.7 \\
\hline & $>12$ & 37.4 \\
\hline \multirow[t]{2}{*}{ Marital status } & Married & 63.7 \\
\hline & Cohabitation & 36.3 \\
\hline \multirow[t]{2}{*}{ Household } & Partner & 86.9 \\
\hline & Partner and family & 13.1 \\
\hline \multirow[t]{3}{*}{ Pregnancy acceptance } & Very bad/bad & 7.7 \\
\hline & Neither good or bad & 3.3 \\
\hline & Good/very good & 89.0 \\
\hline
\end{tabular}

employed (89.0\%), and had more than 9 years of schooling (90.1\%). Most participants were living with the partner without any other family members in the household (76.9\%), and had a good or very good pregnancy acceptance (89.0\%). More than a half $(62.6 \%)$ of the participants were between 30 and 39 years of age $(M=31.25, S D=4.52)$ and belonged to a high or a medium socioeconomic level (59.0\%; see Table 1$)$.

No significant associations or differences were found between the participants who completed and those who did not complete all assessment waves, in terms of sociodemographic characteristics: nationality, ethnicity, religion, age, socioeconomic level, occupational status, schooling, marital status, and household. Significant associations were found on pregnancy acceptance, $\chi^{2}(4)=13.05, P=.011$. Participants who completed all assessments reported better pregnancy acceptance at the first trimester of pregnancy than did participants who did not complete all assessment waves. No significant differences were observed between participants who completed and those who did not complete all assessment waves regarding the study variables: attachment tendencies (avoidance and anxiety dimensions) and coparenting representations (lack of support, conflict, disagreement, and undermining).

\section{2 | Procedure}

This study was conducted in accordance with the Declaration of Helsinki (World Medical Association, 2001) and received previous approval from all institutions involved. Participants were recruited in two obstetrics outpatients units after the first fetal ultrasound (8-14 gestational weeks). Two strategies were used to recruit the participants: (a) directly, when men were in the obstetrics outpatient unit accompanying their pregnant partner; and (b) through contact with their pregnant partners, when they were not accompanying them. Aims and procedures of the study were explained, and men willing to participate signed an informed consent form. This study had a longitudinal design with four online assessment waves: (a) first trimester of pregnancy (8-14 gestational weeks), (b) third trimester of pregnancy (28-32 gestational weeks), (c) 1 month' postpartum (2-4 weeks' postpartum), and (d) 6 months' postpartum (24-26 weeks' postpartum). Participants repeatedly completed the same measures in the four assessment waves.

\section{3 | Measures}

\subsection{1 | Sociodemographic characteristics}

The Socio-Demographic Questionnaire (Figueiredo, Teixeira, Conde, Pinto, \& Sarmento, 2009) was used to assess men's sociodemographic characteristics. This questionnaire includes items concerning men's nationality, ethnicity, age, socioeconomic level (Graffar's classification of occupation), occupational status, years of schooling, marital status, household, and pregnancy acceptance; items are scored on a Likerttype scale of 0 (very bad) to 4 (very good).

\subsection{2 | Attachment tendencies}

The Experiences in Close Relationships Scale (ECR; Brennan Clark, \& Shaver, 1998) was used to assess men's attachment tendencies (avoidance and anxiety dimensions). The ECR is a 36-item self-report scale scored on a Likerttype scale of 1 (strongly disagree) to 7 (strongly agree) and is comprised of two subscales designed to assess the avoidance (18 items) and the anxiety (18 items) dimension of adult attachment. Participants rate how well each statement describes their typical feelings in romantic relationships. Higher scores on the Avoidance and Anxiety subscales indicate higher levels of attachment avoidance and attachment anxiety, respectively. The Portuguese version of the ECR showed good internal consistency, $\alpha=.88$ for the Avoidance subscale; and .86 for the Anxiety subscale (Paiva \& Figueiredo, 2010). In the present sample, Cronbach's $\alpha$ ranged from .81 to .82 for the Avoidance subscale and from .82 to .83 for the Anxiety subscale.

\subsection{3 | Coparenting representations}

The Coparenting Relationship Scale-Father's Prenatal Version (CRS-FPV; Pinto, Figueiredo, \& Feinberg, 2019) was used to assess men's coparenting representations. The CRS-FPV is a prenatal version adapted from the Coparenting 
Relationship Scale (Feinberg, Brown, \& Kan, 2012) to assess coparenting in men during pregnancy. This measure is a self-report scale comprised of 30 items scored on a Likert-type scale of 0 (strongly disagree) to 6 (strongly agree) and by four subscales that assess four dimensions of coparenting: (a) the Lack of Coparenting Support subscale, which assesses one's perception of lack of support from the other coparent (e.g., "My partner make me feel like I will be the best possible parent for our child"); (b) the Coparenting Conflict subscale, which assesses coparents' perception about the exposure of the infant to conflicts related to their education (e.g., "Do you find yourself in a mildly tense or sarcastic interchange with your partner?"); (c) the Coparenting Disagreement subscale, which assesses the degree to which each coparent will disagree with matters related to the infant (e.g., "My partner and I have the same goals for our child"); and (d) the Coparenting Undermining subscale, which assesses one's perception that coparenting will be regulated by critics, guilt, and competition between the coparents (e.g., "My partner does not trust my abilities as a parent"). The CRS-FPV showed good internal consistency, $\alpha=.85$ for the total scale; .94 for the lack of Coparenting Support subscale; .90 for the Coparenting Conflict subscale; .79 for the Coparenting Disagreement subscale; and .69 for the Coparenting Undermining subscale. In the present sample, Cronbach's $\alpha$ s ranged from .87 to .89 for the Lack of Coparenting Support subscale; from .91 to .94 for the Coparenting Conflict subscale; from .78 to .79 for the Coparenting Disagreement subscale; and from .72 to .74 for the Coparenting Undermining subscale.

\subsection{Data analytic strategy}

Growth curve models were estimated using multilevel modeling (e.g., Duncan, Duncan, \& Strycker, 2006) to analyze the association between men's attachment (avoidance and anxiety dimensions) and coparenting representations at the first trimester of pregnancy and from the first trimester of pregnancy to 6 months' postpartum. Time 0 was defined as the date of the first assessment at the first trimester of pregnancy (baseline), and the time variable was scored in weeks from the baseline to 6 months' postpartum. The intercept in the growth curve model refers to the outcome variables (men's coparenting representations of lack of support, conflict, disagreement, and undermining) at the baseline (first trimester of pregnancy), and the slope for time represents the extent to which the outcome variables change each week. Scale scores of men's coparenting representations (CRS-FPV subscales scores: Lack of Support, Conflict, Disagreement, and Undermining), attachment tendencies of avoidance (ECR Avoidance subscale scores), and attachment tendencies of anxiety (ECR Anxiety subscale scores) were examined at each assessment wave. Attachment tendencies of avoidance and anxiety (time-varying effects centered on their grand means) were included in the models as fixed effects. Different models were performed for each outcome variable. Pregnancy acceptance at the first trimester of pregnancy was included as a covariate in all the models, as significant associations were found between participants who completed and those who did not complete all assessment waves on pregnancy acceptance at the first trimester of pregnancy. Significant interactions with continuous predictors were interpreted and graphed using 1 $S D$ above and below the grand mean of the predictor variables as high and low values for those variables. Deviance difference tests were performed between unconditional models and models with predictors to examine model fit improvements.

Statistical analyses were performed in a pairwise personperiod data set using SPSS Version 22.0 (SPSS Inc., USA). Each participant had a record for each time point. Thus, the resulting data consisted of 344 potential observations (86 participants $\times 4$ time points). The effect size $r$ (Rosenthal, Rosnow, \& Rubin, 2000) was estimated for all significant effects and interpreted according to Cohen's (1988) guidelines.

\section{3 | RESULTS}

\section{1 | Preliminary analysis}

Descriptive statistics ( $M$ and $S D$ ) were performed for all study variables (scores of attachment tendencies of avoidance and anxiety, and coparenting representations of lack of support, conflict, disagreement, and undermining) at each assessment (see Table 2).

Statistical assumptions regarding the growth curve models were tested. The first statistical assumption concerns the presence of correlations between the study variables. Significant small-to-medium size correlations were found among the study variables at the baseline, revealing that these scores covary. Significant correlations were found between men's attachment tendencies of avoidance and coparenting representations at the first trimester of pregnancy, $r s=.310-.382$, $P$ s $<$.05. Likewise, significant correlations were found between men's attachment tendencies of anxiety and coparenting representations at the first trimester of pregnancy, $r s=.248-.404, P \mathrm{~s}<.05$. No correlation was found between men's attachment tendencies of anxiety and coparenting representation of conflict at the first trimester of pregnancy. In addition, significant intercorrelations were found between men's coparenting representations, $r \mathrm{~s}=.211-.495, P_{\mathrm{s}}<.05$.

The second statistical assumption concerns the performance of deviance difference tests to analyze if the models including both the time and the predictors (attachment tendencies of avoidance and anxiety) explain more variance than do the models only including the time. Deviance difference tests showed that the models provided good fit to the data, $\chi^{2}(5)=64.23, P<.001, \chi^{2}(5)=36.60$, 
T A B L E 2 Descriptive statistics of study variables at each assessment wave

\begin{tabular}{|c|c|c|c|c|c|c|c|c|}
\hline & \multicolumn{4}{|c|}{ Pregnancy } & \multicolumn{4}{|c|}{ Postpartum } \\
\hline & \multicolumn{2}{|c|}{ 1st trimester } & \multicolumn{2}{|c|}{ 3rd trimester } & \multicolumn{2}{|c|}{1 month } & \multicolumn{2}{|c|}{6 months } \\
\hline & $\bar{M}$ & $S D$ & $\bar{M}$ & $S D$ & $\bar{M}$ & $S D$ & $\bar{M}$ & $S D$ \\
\hline Attachment anxiety $^{\mathrm{a}}$ & 2.97 & 1.06 & 2.81 & 1.08 & 2.87 & 0.93 & 2.83 & 1.04 \\
\hline Lack of coparenting support ${ }^{\mathrm{b}}$ & 5.58 & 11.89 & 7.05 & 11.80 & 9.24 & 14.54 & 14.45 & 17.78 \\
\hline Coparenting undermining $^{\mathrm{e}}$ & 4.66 & 3.37 & 3.62 & 2.66 & 4.48 & 3.71 & 4.48 & 3.03 \\
\hline
\end{tabular}

Note. ${ }^{\text {a }}$ Scores range between 1 and $7 .{ }^{\mathrm{b}}$ Scores range between 0 and $90 .{ }^{\mathrm{c}}$ Scores range between 0 and $30 .{ }^{\mathrm{d}}$ Scores range between 0 and $36 .{ }^{\mathrm{e}} \mathrm{S}$ cores range between 0 and 24.

$P<.001, \chi^{2}(5)=56.66, P<.001$, and,$\chi^{2}(5)=18.00$, $P=.003$, respectively.

Finally, the effects of time also were explored in all the outcome variables (men's coparenting representations). Main effects for time were found in men's coparenting representations of lack of support and disagreement. From the first trimester of pregnancy to 6 months' postpartum, men's coparenting representations of lack of support increased, and men's coparenting representations of disagreement decreased. Men's coparenting representations of lack of support increased, on average, 0.19 units per week, $P<.001$, effect size $r=.363$, and men's coparenting representations of disagreement decreased, on average, 0.06 units per week, $P=.013$, effect size $r=.200$. No main effects for time were found on men's coparenting representations of conflict and undermining.

\section{2 | Associations between men's attachment and coparenting representations at the first trimester of pregnancy}

Main effects of men's attachment tendencies of avoidance were found on men's coparenting representations of lack of support (see Table 3). At the first trimester of pregnancy, higher attachment avoidance was associated with higher perceived lack of coparenting support, $b=0.57, P<.001$, effect size $r=.294$. No main effects of men's attachment tendencies of avoidance were found on men's coparenting representations of conflict, disagreement, and undermining. No main effects of men's attachment tendencies of anxiety were found on men's coparenting representations of lack of support, conflict, disagreement, and undermining.

\subsection{Associations between men's attachment and coparenting representations from the first trimester of pregnancy to 6 months' postpartum}

Interaction effects of men's attachment tendencies of avoidance and time were found on men's coparenting representations of lack of support, conflict, and disagreement (see Table 3). Higher attachment avoidance was associated with a higher increase on perceived lack of coparenting support from the first trimester of pregnancy to 6 months' postpartum, $b=0.03, P<.001$, effect size $r=.401$ (see Figure 1).

Higher attachment avoidance was associated with an increase on perceived coparenting conflict from the first trimester of pregnancy to 6 months' postpartum whereas low attachment avoidance was associated with a decrease on perceived coparenting conflict, $b=0.01, P=.003$, effect size $r=.260$ (see Figure 2).

Higher attachment avoidance was associated with a lower decrease on perceived coparenting disagreement from the first trimester of pregnancy to 6 months' postpartum, $b=0.01$, $P=.043$, effect size $r=.117$ (see Figure 3). No interaction effects of men's attachment tendencies of avoidance and time were found on men's coparenting representations of undermining.

\section{4 | DISCUSSION}

Significant associations between men's attachment and coparenting representations were found at the first trimester of pregnancy, and from the first trimester of pregnancy to 6 months' postpartum. Regarding associations between men's attachment and coparenting representations at the first trimester of pregnancy, men with higher attachment avoidance were found to perceive higher lack of coparenting support. Regarding associations between men's attachment and coparenting representations from the first trimester of pregnancy to 6 months' postpartum, men with higher attachment avoidance were found to show (a) a steeper increase on perceived lack of coparenting support, (b) an increase on perceived coparenting conflict (whereas men with low attachment avoidance showed a decrease), and (c) a lower decrease on perceived coparenting disagreement.

Talbot et al. (2009) found a negative association between men's secure attachment and coparenting conflict during the postpartum period. The findings of the present study are congruent with this previous study by suggesting associations between men's attachment tendencies of avoidance and 

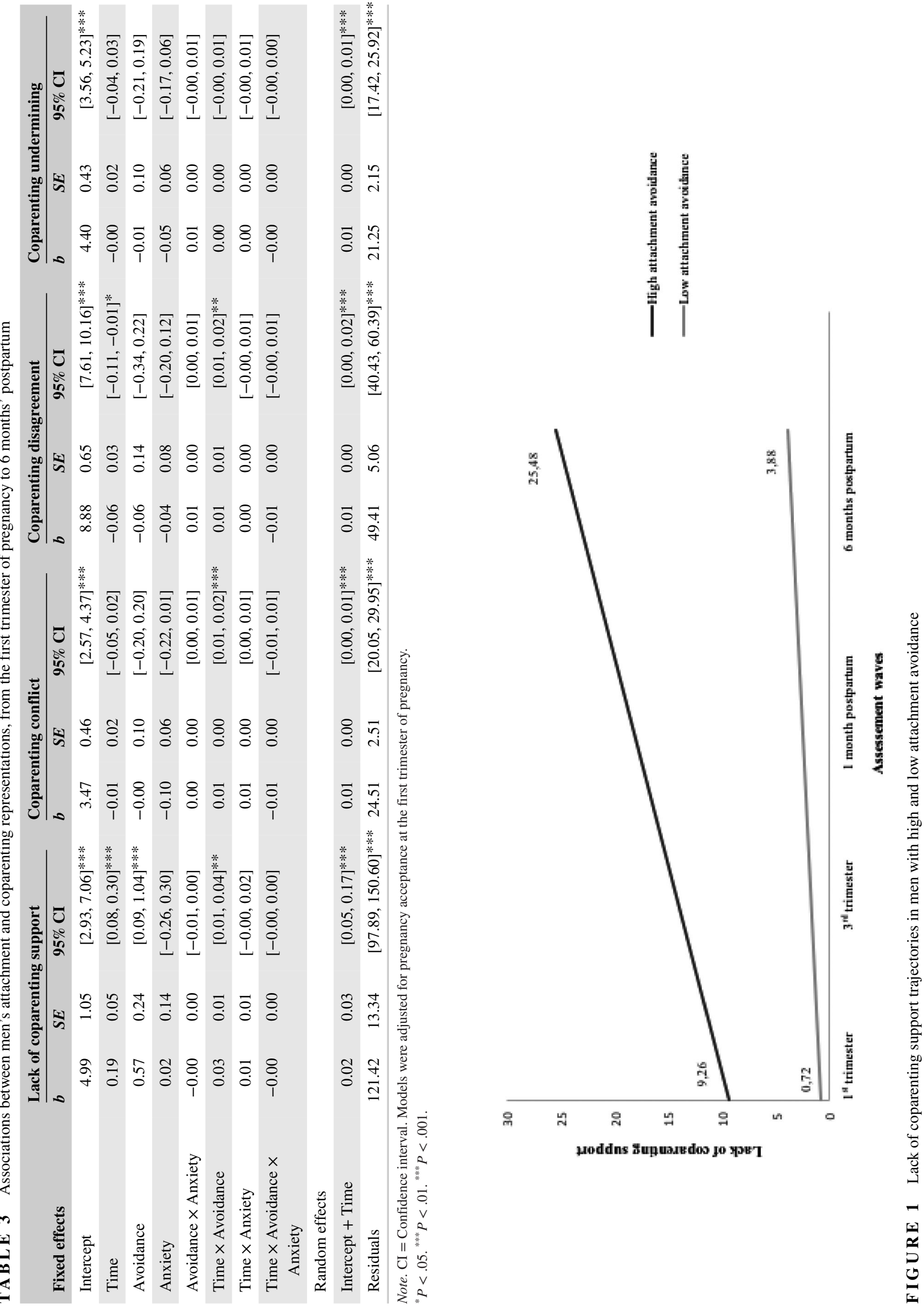

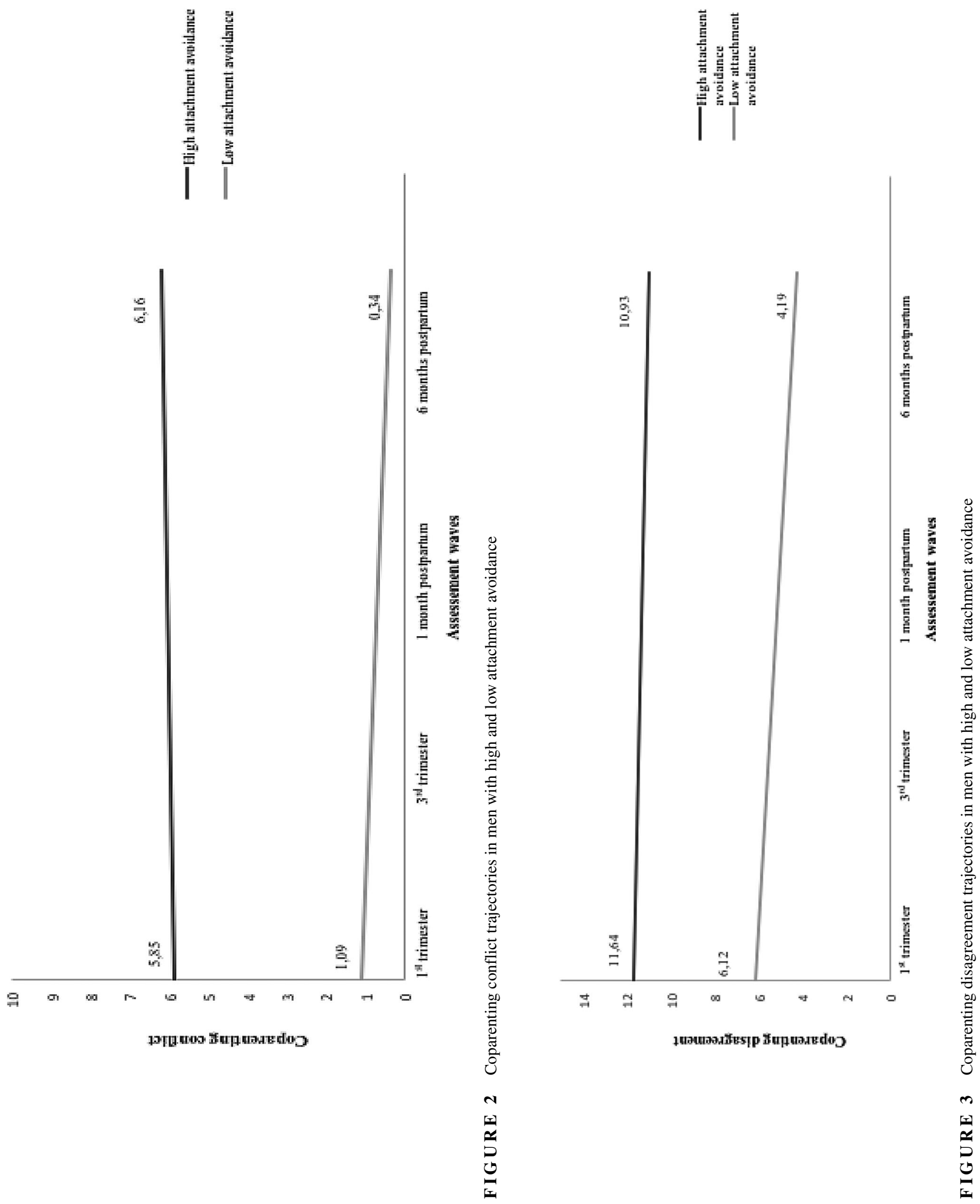

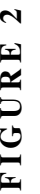

כ) 
coparenting representations of conflict, from early pregnancy to the postpartum period.

These findings provide new empirical evidence for coparenting research by suggesting that attachment tendencies influence men's coparenting representations, shaping the development of coparenting during the transition to parenthood. Results allow us to hypothesize that due to their discomfort with the closeness or dependency and the reluctance to be intimate (e.g., Bartholomew \& Shaver, 1998), men with high attachment avoidance may perceive less support from their coparent, higher conflict and disagreement about matters related to the infant, and more criticism from their coparent during the transition to parenthood. Results also allow us to hypothesize that men with high attachment avoidance could be less involved in the development of their coparenting relationship, aiming to avoid closeness with their coparent.

Men with high attachment avoidance may experience specific difficulties when developing their coparenting relationship during the transition to parenthood similarly to the difficulties experienced in their marital relationship: Lower levels of intimacy and commitment as well as higher perceived conflict have been reported (e.g., Fraley \& Bonanno, 2004; Kafetsios \& Sideridis, 2006; Millings \& Walsh, 2009; Selcuk et al., 2010). These results provide new empirical evidence to attachment theory, suggesting that attachment tendencies of avoidance are associated with the development of maladjusted coparenting representations in men during the transition to parenthood.

A maladjusted (e.g., nonsupportive and undermining) coparenting was identified as the best predictor of children's internalizing and externalizing problems, independently of their developmental stage and family structure (e.g., Lamela, Figueiredo, Bastos, \& Feinberg, 2016; Scrimgeour, Blandon, Stifter, \& Buss, 2013; Teubert \& Pinquart, 2010). To analyze individual differences in the development of coparenting representations during the transition to parenthood using attachment theory as a framework may clarify which psychosocial processes are involved in men's maladjusted coparenting (e.g., nonsupportive and undermining).

\section{1 | Limitations}

Some methodological limitations should be noted. Constructs were assessed through self-report measures. As independent and dependent variables were generated by the same informant, a common-method variance may have inflated the links between the study variables. Despite all measures having exhibited adequate internal consistency, additional observational measures may have provided higher accuracy and reduced possible shared method variance on the study variables. The voluntary nature of the participation in the study may have led to a selection bias. Men who agreed to participate and those who complied with all assessment waves may, in fact, be those who feel more involved and satisfied with the pregnancy and the postpartum experience. Namely, participants that completed all assessments waves reported better pregnancy acceptance at the first trimester of pregnancy than those who did not complete all assessment waves. Thus, pregnancy acceptance at the first trimester of pregnancy was controlled in the models. A larger sample size would have increased statistical power, which would have allowed to highlight other possible links between the variables.

\subsection{Implications for practice and research}

The results of this study suggest that attachment tendencies interfere in the development of coparenting representations in men during the transition to parenthood. Attachment theory can be a useful tool to identify men's specific difficulties when developing a coparenting relationship during the transition to parenthood, and to provide them adequate psychological counseling when needed. In addition, coparenting interventions may also recognize the development of this relationship as an opportunity to shape men's attachment tendencies during the transition to parenthood.

To provide more evidence on the association between attachment and coparenting representations during the transition to parenthood, future studies should focus on both women and men, and also may consider including other variables that could interfere with the development of coparenting representations during the transition to parenthood.

\section{3 | Conclusions}

This study may contribute to coparenting research by showing new evidence on attachment theory as a useful framework to understand how different coparenting representations are developed in men during the transition to parenthood.

\section{ACKNOWLEDGMENTS}

This study was conducted at the Psychology Research Centre (UID/PSI/01662/2013), University of Minho, and was supported by the Portuguese Foundation for Science and Technology and the Portuguese Ministry of Education and Science through National funds and co-financed by FEDER through COMPETE2020 under the PT2020 Partnership Agreement (POCI-01-0145-FEDER-007653). This study was also supported by FEDER Funds through the Programa Operacional Factores de Competitividade-COMPETE and by National Funds through FCT-Fundação para a Ciência e a Tecnologia under Project PTDC/SAU/SAP/116738/2010 and by a PhD grant (SFRH/BD/115048/2016) to the first author.

\section{CONFLICT OF INTEREST}

The authors declare no conflicts of interest. 


\section{ORCID}

Tiago Miguel Pinto

https://orcid.org/0000-0002-7581-8961

Bárbara Figueiredo (iD

https://orcid.org/0000-0002-8209-7445

\section{REFERENCES}

Ainsworth, M. D. S. (1989). Attachments beyond infancy. American Psychologist, 44, 709-716. https://doi.org/10.1037/0003-066X.44. 4.709

Altenburger, L. E., Schoppe-Sullivan, S. J., Lang, S. N., Bower, D. J., $\&$ Kamp Dush, C. M. (2014). Associations between prenatal coparenting behavior and observed coparenting behavior at 9-months postpartum. Journal of Family Psychology, 28, 495-504. https://doi.org/ 10.1037/fam0000012

Ammaniti, M., van IJzendoorn, M. H., Speranza, A. M., \& Tambelli, R. (2000). Internal working models of attachment during late childhood and early adolescence: An exploration of stability and change. Attachment \& Human Development, 2, 328-346. https://doi.org/ 10.1080/14616730010001587

Bartholomew, K. (1990). Avoidance of intimacy: An attachment perspective. Journal of Social and Personal Relationships, 7, 147-178. https://doi.org/10.1177/0265407590072001

Bartholomew, K., \& Shaver, P. R. (1998). Methods of assessing adult attachment. Do they converge? In J. A. Simpson \& W. S. Rholes (Eds.), Attachment theory and close relationships (pp. 25-45). New York, NY: Guilford Press.

Bowlby, J. (1969). Attachment and loss (Vol. I). London, United Kingdom: Hogarth Press.

Brennan, K. A., Clark, C. L., \& Shaver, P. (1998). Self-report measures of adult romantic attachment. In J. A. Simpson \& W. S. Rholes (Eds.), Attachment theory and close relationships (pp. 46-76). New York, NY: Guilford Press.

Campbell, L., Simpson, J. A., Kashy, D. A., \& Rholes, W. S. (2001). Attachment orientations, dependence, and behavior in a stressful situation: An application of the Actor-Partner Interdependence Model. Journal of Social and Personal Relationships, 18, 821-843. https://doi.org/10.1177/0265407501186005

Cohen, J. (1988). Statistical power analysis for the behavioral sciences (2nd ed.). Hillsdale, NJ: Erlbaum.

Collins, N. L., \& Allard, L. M. (2001). Cognitive representations of attachment: The content and function of working models. In G. J. O. Fletcher \& M. S. Clark (Eds.), Blackwell handbook of social psychology: Vol. 2. Interpersonal processes (pp. 60-85). London, United Kingdom: Blackwell.

Collins, N. L., \& Feeney, B. C. (2000). A safe haven: An attachment theory perspective on support seeking and caregiving in intimate relationships. Journal of Personality and Social Psychology, 78, 10531073. https://doi.org/10.1037/0022-3514.78.6.1053

Collins, N. L., \& Feeney, B. C. (2004). Working models of attachment shape perceptions of social support: Evidence from experimental and observational studies. Journal of Personality and Social Psychology, 87, 363-383. https://doi.org/10.1037/0022-3514.87.3.363

Collins, N. L., Ford, M. B., Guichard, A. C., \& Allard, L. M. (2006). Working models of attachment and attribution processes in intimate relationships. Personality and Social Psychology Bulletin, 32, 201219. https://doi.org/10.1177/0146167205280907
Cowan, C. P., \& Cowan, P. A. (2000). When partners become parents: The big life change for couples. Mahwah, NJ: Erlbaum.

Duncan, T., Duncan, S., \& Strycker, L. (2006). An introduction to latent growth curve modeling: Concepts, issues and applications (2nd ed.). Mahwah, NJ: Erlbaum.

Favez, N., Frascarolo, F., Scaiola, C., \& Corboz-Warnery, A. (2013). Prenatal representations of family in parents and coparental interactions as predictors of triadic interactions during infancy. Infant Mental Health Journal, 34, 25-36. https://doi.org/10.1002/imhj.21372

Feinberg, M. (2002). Coparenting and the transition to parenthood: A framework for prevention. Clinical Child \& Family Psychology Review, 5, 173-195. https://doi.org/10.1023/A:1019695015110

Feinberg, M. (2003). The internal structure and ecological context of coparenting: A framework for research and intervention. Parenting: Science and Practice, 3, 85-132. https://doi.org/10.1207/ S15327922PAR0302_01

Feinberg, M. E., Brown, L. D., \& Kan, M. L. (2012). A multi-domain self-report measure of coparenting. Parenting: Science and Practice, 12, 1-21. https://doi.org/10.1080/15295192.2012.638870

Figueiredo, B. (2014). Mother- and father-to-infant emotional involvement. In C. M. Pariante, S. Conroy, P. Dazzan, L. Howard, S. Pawlby, \& T. Seneviratne (Eds.), Perinatal psychiatry: The legacy of Channi Kumar (pp. 129-143). Oxford, United Kingdom: Oxford University Press.

Figueiredo, B., Teixeira, C., Conde, A., Pinto, A., \& Sarmento, P. (2009). Utentes da consulta externa de ginecologia/obstetrícia da Maternidade Júlio Dinis [Patients of the Júlio Dinis obstetricts outpatient unit]. Revista Portuguesa de Psicologia, 41, 45-64. Retrieved from http://hdl.handle.net/123456789/472

Fraley, R. C., \& Bonanno, G. A. (2004). Attachment and loss: A test of three competing models on the association between attachmentrelated avoidance and adaptation to bereavement. Personality and Social Psychology Bulletin, 30, 878-890. https://doi.org/10.1177/ 0146167204264289

Fraley, R. C., \& Roberts, B. W. (2005). Patterns of continuity: A dynamic model for conceptualizing the stability of individual differences in psychological constructs across the life course. Psychological Review, 112, 60-74. https://doi.org/10.1037/0033-295X.112.1.60

Kafetsios, K., \& Sideridis, G. D. (2006). Attachment, social support and well-being in young and older adults. Journal of Health Psychology, 11, 863-875. https://doi.org/10.1177/1359105306069084

Lamela, D., Figueiredo, B., Bastos, A., \& Feinberg, M. (2016). Typologies of post-divorce coparenting and parental well-being, parenting quality and children's psychological adjustment. Child Psychiatry \& Human Development, 47, 716-728. https://doi.org/10.1007/ s10578-015-0604-5

Mikulincer, M., Shaver, P. R., \& Pereg, D. (2003). Attachment theory and affect regulation: The dynamics, development, and cognitive consequences of attachment-related strategies. Motivation and Emotion, 27, 77-102. https://doi.org/10.1023/A:1024515519160

Millings, A., \& Walsh, J. (2009). A dyadic exploration of attachment and caregiving in long-term couples. Personal Relationships, 16, 437453. https://doi.org/10.1111/j.14756811.2009.01232.x

Paiva, C., \& Figueiredo, B. (2010). Versão portuguesa da escala "Experiences in Close Relationships" (ECR) [Experiences in Close Relationships Questionnaire (ECR) Portuguese version]. In Avaliaç\&atilde;o Psicológica (Vol. IV): Instrumentos Validados para a população Portuguesa (pp. 81-102). Porto, Portugal: Almedina.

Pinto, T. M., Figueiredo, B., \& Feinberg, M. E. (2019). The Coparenting Relationship Scale-Fathers' Prenatal Version. Journal of 
Adult Development. 26(3), 201-208. https://doi.org/10.1007/s10804018-9308-y

Rholes, W. S., Simpson, J. A., Campbell, L., \& Grich, J. (2001). Adult attachment and the transition to parenthood. Journal of Personality and Social Psychology, 81, 421-435. https://doi.org/10.1037/ 0022-3514.81.3.421

Rosenthal, R., Rosnow, R. L., \& Rubin, D. B. (2000). Contrasts and effect sizes in behavioral research: A correlational approach. Cambridge, United Kingdom: Cambridge University Press.

Scrimgeour, M. B., Blandon, A. Y., Stifter, C. A., \& Buss, K. A. (2013). Cooperative coparenting moderates the association between parenting practices and children's prosocial behavior. Journal of Family Psychology, 27, 506-511. https://doi.org/10.1037/a0032893

Selcuk, E., Zayas, V., \& Hazan, C. (2010). Beyond satisfaction: The role of attachment in marital functioning. Journal of Family Theory and Review, 2, 258-279. https://doi.org/10.1111/ j.17562589.2010.00061.x

Shaver, P. R., \& Hazan, C. (1988). A biased overview of the study of love. Journal of Social and Personal Relationships, 5, 473-501. https://doi.org/10.1177/0265407588054005

Shaver, P. R., \& Mikulincer, M. (2007). Adult attachment strategies and the regulation of emotion. In J. J. Gross (Ed.), Handbook of emotion regulation (pp. 446-465). New York, NY: Guilford Press.

Simpson, J. A., Ickes, W., \& Grich, J. (1999). When accuracy hurts: Reactions of anxious-ambivalent dating partners to a relationshipthreatening situation. Journal of Personality and Social Psychology, 76, 754-769. https://doi.org/10.1037/0022-3514.76.5.754

Simpson, J. A., Rholes, W. S., \& Nelligan, J. S. (1992). Support seeking and support giving within couples in an anxiety-provoking situation: The role of attachment styles. Journal of Personality and Social Psychology, 62, 434-446. https://doi.org/10.1037/0022-3514.62.3.434
Talbot, J. A., Baker, J. K., \& McHale, J. P. (2009). Sharing the love: Prebirth adult attachment status and coparenting adjustment during early infancy. Parenting: Science and Practice, 9, 56-77. https://doi.org/10.1080/15295190802656760

Teubert, D., \& Pinquart, M. (2010). The association between coparenting and child adjustment: A meta-analysis. Parenting: Science and Practice, 10, 286-307. https://doi.org/10.1080/15295192.2010. 492040

Van Egeren, L. A. (2003). Prebirth predictors of coparenting experiences in early infancy. Infant Mental Health Journal, 24, 278-295. https://doi.org/10.1002/imhj.10056

Van Egeren, L. A. (2004). The development of coparenting over the transition to parenthood. Infant Mental Health Journal, 25, 453-477. https://doi.org/10.1002/imhj.20019

Van Egeren, L. A., \& Hawkins, D. P. (2004). Coming to terms with coparenting: Implications of definition and measurement. Journal of Adult Development, 11, 165-178. https://doi.org/10.1023/ B:JADE.0000035625.74672.0b

World Medical Association. (2001). World Medical Association Declaration of Helsinki. Ethical principles for medical research involving human subjects. Bulletin of the World Health Organization, 79(4), 373.

How to cite this article: Pinto TM, Figueiredo B. Attachment and coparenting representations in men during the transition to parenthood. Infant Ment Health J. 2019;1-10. https://doi.org/10.1002/21820 